\title{
Complementary feeding practices in rural areas of Telangana: A hospital based, cross-sectional, descriptive study
}

\author{
K Sailaja ${ }^{1}$, Kiran $\mathbf{H}^{2}$ \\ ${ }^{1}$ Dr. K. Sailaja, DNB, Pediatrics, Associate Professor, ${ }^{2}$ Dr. Kiran Haridas, Assistant Professor, Department of Pediatrics, \\ Kamineni Institute of Medical Sciences, Narketpally, Naigonda (Dist), Telangana, India
}

Address for Correspondence: Dr. Sailaja K, D4-10,KIMS, Narketpally, Nalgonda (Dist), Telangana. Emailsailajakamaraju@gmail.com

\begin{abstract}
Background: Introduction of semi solid/solid food i.e., complementary feeding time is very vulnerable period during infancy. To prevent malnutrition knowledge of optimal feeding practices is essential for mothers. Objective: To study currently existing complementary feeding practices and assess the knowledge and practice gap. Study design: Hospital based, cross-sectional, descriptive study. Setting: In a tertiary care teaching hospital of rural Telangana. Participants: Total 220 mothers with children in the age group of 6-23 months of age. Methods: Participants were randomly selected after informed consent. Data regarding currently following complementary feeding practices was collected in the predesigned, semi-structured questionnaire and analyzed. Results: Only 40.9\% of mothers initiated complementary feeding at the recommended age. Although age appropriate quantity of food was received by $66.4 \%$ of subjects only $25.5 \%$ subjects were receiving at recommended frequency. $77.7 \%$ of mothers were giving home made preparations. Diversity of feeds was observed in $23 \%$ of children. Conclusions: As there is increasing evidence for the positive impact of feeding counseling on energy and nutrient intake and growth in children of less than two years, changes in individual's behavior, supplemental interventions will be needed. Effective nutrition actions do exist but should be implemented on a sufficiently large scale to reduce the burden of malnutrition.
\end{abstract}

Key words: Complementary feeding, Quality, Quantity, Frequency.

\section{Introduction}

Malnutrition is responsible, directly or indirectly, for over half of all childhood deaths. Infants and young children are at increased risk of malnutrition from six months of age onwards, when breast milk alone is no longer sufficient to meet all nutritional requirement and complementary feeds (CF) need to be started [1]. This means complementing semi solid/solid food along with breast milk after child attains age of 6 months [2]. The transition from exclusive breastfeeding (EBF) to family foods referred to as complementary feeding (CF) typically covers the period from 6 to 18-23 months of age and is very vulnerable period. It is the time when malnutrition starts in many infants contributing significantly to the high prevalence of malnutrition in children under five years of age world- wide. WHO estimates that 2 out of 5 children are stunted in lowincome countries.[3] Complementary feeds should be timely, adequate, safe and properly fed [1]. Missing this age can lead to feeding fussiness later [2]. Good

Manuscript received: $04^{\text {th }}$ March 2016

Reviewed: $10^{\text {th }}$ March 2016

Author Corrected; $20^{\text {th }}$ March 2016

Accepted for Publication: $31^{\text {st }}$ March 2016 nutrition signals the realization of people's rights to food and health. Without good nutrition human beings cannot achieve their full potential [4]. .Hence mothers are expected to make the "weaning bridge" or the bridge of complementary feeding to carry the children across the pit of malnutrition during liquid to solid transition [5].

Optimal Infant and Young Child Feeding (IYCF) Practices recommend age appropriate $\mathrm{CF}$ for children of 6-23 months of age, while continuing breast feeding. According to IYCF children should receive food from 4 or more food groups [1. Grains, roots, and tubers, legumes and nuts, 2. Dairy products, 3.Flesh foods (meat, fish, poultry), 4. Eggs 5. Vitamin A rich fruits and vegetables; 6 . Other fruits and vegetables] and fed for a minimum number of times i.e.,2 times for breast fed infants 6-8 months, 3 times for breast fed children 9-23 months; 4 times for non-breast fed children of 623 months. It also said adequate total energy intake can 
also be ensured by addition of one to two nutritious snacks between the 3 main meals and should not replace meals [1].

Poor IYCF practices are associated with poor nutritional outcomes. As stated in The Healthy Growth Project [6] households and communities should participate as the main protagonists of healthy child growth and development.

Hence we have taken up the study to know the currently existing complementary feeding practices and assess the knowledge and practice gap in rural Telangana where our college is located.

\section{Methods}

This cross-sectional, descriptive, hospital based study was conducted in the department of Pediatrics, of a rural based medical college hospital, Telangana from October 2015 to January 2016. The study was approved by the Institutional ethics committee. 220 mothers with infants and young children of 6-23 months age who were attending to our well baby clinics during the study period and willing to participate were randomly included in the study. Children who were not accompanied by their mothers, who were born as preterm, or IUGR or low birth weight, children with chronic illnesses and non-willing mothers were excluded from the study. Data regarding currently following complementary feeding practices was collected in the predesigned, semi-structured questionnaire. Questionnaire was administered by the authors and other trained investigators. Socio-economic status was assessed by modified Kuppuswamy socio economic scale [7]

Demographic profile and complementary feeding practices in terms of time of initiation of CF, Quality, Quantity,, frequency, consistency, and information about extra snacks were elicited.

Quantity of food was assessed by showing a standard $150 \mathrm{ml}$ katori. The consistency of food was assessed by showing WHO teaching slide [8] Adequacy of feeds was assessed according to WHO recommendations. Table-1[9]

Analysis of the data was done using SPSS software version 19.0. Simple proportions were calculated for assessing various indicators.

\section{Results}

A total of 220 mothers with children of 6-23 months of age were included in the study. The socio-demographic profile of these subjects was shown in Table-2. Of 220 children $132(60 \%)$ were males, $88(40 \%)$ were females. There were 64 (29.1\%) subjects in 6-8 months of age, 34 (15.5\%) were in 9-11 months of age, $122(55.5 \%)$ in 12-23 months of age constituting the major part.

Table-1: Quantity and Frequency recommended for children of 6-23 months

\begin{tabular}{|l|l|l|l|l|}
\hline AGE & $\begin{array}{l}\text { Energy needed per } \\
\text { day in addition to } \\
\text { breast-milk }\end{array}$ & Texture & Frequency & $\begin{array}{l}\text { Amount of food for } \\
\text { an average child }\end{array}$ \\
\hline $6-8$ months & $220 \mathrm{kcal}$ per day & $\begin{array}{l}\text { Thick porridge, well } \\
\text { mashed foods }\end{array}$ & $\begin{array}{l}\text { 2-3 meals per day. } \\
\text { Depending on } \\
\text { child's appetite } 1-2 \\
\text { snacks. }\end{array}$ & $\begin{array}{l}2-3 \text { tablespoonfuls } \\
\text { per feed, increasing } \\
\text { to } 1 / 2 \text { of a } 250 \mathrm{ml} \\
\text { cup. }\end{array}$ \\
\hline $9-11$ months & $300 \mathrm{kcal}$ per day & Mashed foods & $\begin{array}{l}3-4 \text { meals per day. } \\
1-2 \text { snacks } \\
\text { depending on child's } \\
\text { appetite }\end{array}$ & $\begin{array}{l}1 / 2 \text { of a } 250 \mathrm{ml} \text { cup } \\
12-23 \text { months }\end{array}$ \\
\hline \multirow{2}{*}{$550 \mathrm{kcal}$ per day } & $\begin{array}{l}\text { Family foods, } \\
\text { mashed if necessary } \\
1-2 \text { snacks } \\
\text { depending on child's } \\
\text { appetite. }\end{array}$ & $\begin{array}{l}1 / 4 \text { to full } 250 \mathrm{ml} \\
\text { cup/bowl. }\end{array}$ \\
\hline
\end{tabular}

$129(58.6 \%)$ subjects belong to nuclear family and remaining 91(41.4\%) to joint family.60 (27.3\%) mothers and 64 (29.1\%) fathers had education of inter and above. 62 (28.2\%) mothers and 59 (26.8\%) fathers did not have any formal 
education. Majority of study subjects 106 (48.2\%) belong to upper lower (class iv), and 96 (43.6\%) to lower middle (class III), $18(8.2 \%)$ to upper middle (class II) and no subjects were there from lower (class V), or upper (class I). Very few10 (4.5\%) children belong to the birth order of three and others were either first $112(50.9 \%)$, or second $98(44.5 \%)$ in birth order which is an encouraging factor.

Table 2: Socio-Demographic Profile of Participants

\begin{tabular}{|c|c|}
\hline Variable & Frequency \% \\
\hline $\begin{array}{l}\text { Age of children } \\
6-8 \text { months } \\
9-11 \text { months } \\
12-23 \text { months }\end{array}$ & $\begin{array}{l}64(29.1) \\
34(15.5) \\
122(55.5)\end{array}$ \\
\hline $\begin{array}{l}\text { Father's Education } \\
\text { Not Educated. } \\
\text { Primary } \\
\text { High School } \\
\text { Inter \& above }\end{array}$ & $\begin{array}{l}59(26.8) \\
38(17.2) \\
59(26.8) \\
64(29.1)\end{array}$ \\
\hline $\begin{array}{l}\text { Mother's occupation } \\
\text { Housewife } \\
\text { working }\end{array}$ & $\begin{array}{l}168(23.6) \\
58(76.4)\end{array}$ \\
\hline $\begin{array}{l}\text { Family Type } \\
\text { Joint } \\
\text { Nuclear }\end{array}$ & $\begin{array}{l}91(41.4) \\
129(58.6)\end{array}$ \\
\hline $\begin{array}{l}\text { Birth order } \\
\text { First } \\
\text { Second } \\
\text { Third }\end{array}$ & $\begin{array}{l}112(50.9) \\
98(44.5) \\
10(4.5)\end{array}$ \\
\hline $\begin{array}{l}\text { Source of Knowledge } \\
\text { Cultural ritual } \\
\text { Friends } \\
\text { Media } \\
\text { Qualified person }\end{array}$ & $\begin{array}{l}146(66.4) \\
36(16.4) \\
6(2.7) \\
32(14.5)\end{array}$ \\
\hline
\end{tabular}

Table 3: Food items used in different age groups

\begin{tabular}{|l|l|l|}
\hline 6-8 months & 9-11 months & 12-23 months \\
\hline Not started -6.3\% & Not started-5.9\% & Commercial preparations-8.2\% \\
Commercial food- $28.2 \%$ & Commercials-5.9\% & Soft rice-13.1\% \\
Rice- $25 \%$ & Rice-23.5\% & Energy dense- 13.15 \\
Energy dense $-21.9 \%$ & Rice, ghee, boiled vegetables, dairy & Rice,dal,greens-13.1\% \\
Rice,dal, ghee-18.8\% & products-41.1\% & Rice with dal-29.5\% \\
& Above groups with dal- 23.5\% & With diversity-23\% \\
\hline
\end{tabular}

EBF: In the study population $82(37.3 \%)$ of mothers had given EBF for 6 months. 64(29.1\%) had given EBF for $<6$ months and started on mixed feeding with buffalo milk. However $8(12.5 \%)$ mothers of this group initiated CF at the right time and others who were continuing mixed feeding at the time of interview were counseled accordingly. 74 (33.6\%) of mothers were still continuing EBF for $>6$ months and also received proper advice. The reason for continuing prolonged EBF was that mothers felt their milk was enough for the baby. Both the practices were not appropriate.

Complementary feeding: Less than half 90 (40.9\%) of mothers initiated CF at the recommended age. 48(21.8\%) mothers started CF early. Reason for early initiation of CF was "not enough milk" and "excessive cry of the baby." 
Remaining 74 (33.6\%) subjects received CF after 6 months. Reason for late initiation was lack of knowledge of CF in parents and was counseled. Age appropriate quantity of food was received by $146(66.4 \%)$ of subjects. However, a small proportion i.e., $25.5 \%$ subjects were receiving at recommended frequency. This practice will also lead to malnutrition. As not only quantity maintaining proper frequency is also essential. Interestingly $171(77.7 \%)$ of mothers were giving home made preparations and commercial preparations was preferred by small number of mothers i.e.,41(18.6\%). Consistency was age appropriate in the current study. Smaller proportions of mothers were giving others like greens $(15.9 \%)$, egg (12.7\%), non-veg (0.9\%). Snacks as extra supplementation was received by $178(80.9 \%)$ of children in which $137(77 \%)$ of them were receiving biscuits. But only 98(44.5\%) mothers were giving snacks regularly. Generally used food items in this area were shown in Table-3.

Statistical analysis revealed time of initiation of CF was significantly co-related to mother's educational status and father's educational status with $\mathrm{p}<0.05(0.000)$ in both the cases. Socio-economic status also showed an impact with $\mathrm{p}<$ 0.05 (0.014). Educational status mother, father, and their socio-economic status showed a significant correlation to quality of food as well with $\mathrm{p}<0.05$ ( $0.001,0.001,0009$ respectively) Regarding quantity rather than mother's education father's education and socio economic status had got positive impact with $p<0.05(0.000$, $)$ Father's participation in upbringing of the children was appreciated. And tendency for commercial preparation was more in educated group. Maintaining the frequency of foods was not correlated to mother's educational status or socio-economic status ( $\mathrm{p}>0.05$ ). But father's educational status had an effect with $\mathrm{p}<0.05$. Similar finding was observed in maintaining appropriate quantity of CF . Birth order, type of family or mother's occupation did not have any statistically significant effect on complementary feeding practices with $\mathrm{p}>0.05$.

\section{Discussion}

In the present study $40.9 \%$ of mothers started complementary feeding at the recommended time. But in the report of NFHS-4 2015-16 state fact sheets, Telangana [10] reported $56.4 \%$ of children age $6-8$ months were receiving solid or semi solid food and breast milk. As in the current study age groups from 623 months were included it might have caused the difference. In the study of Aggarwal et al [11 ] from Delhi it was much lower i.e., $17.5 \%$ had started at recommended time and a study from Delhi slums also reported [12] a small proportion i.e., $16.6 \%$ at the recommended age. This difference could be due to the cultural belief of starting of solids at 7 months as a ritual in this area. But in a study done by Vartika Saxena from Rishikesh [13] it was much higher i.e., $70.1 \%$ of mothers started at right time. But their study was done in the community. Another study from urban slum, Kolkata also reported 71.66\% [14]. S. Rao et al study from Udupi and Mangalore [15] observed 77.5\% but in their study literate mothers constituted more proportion.

Delayed CF: In the current study $33.6 \%$ of mothers had initiated $\mathrm{CF}$ after 6 months and not consistent with Rishikesh study where it was much lower (13\%) and But in Delhi study it was high $70 \%$. Aggarwal at el study also reported it $77 \%$ much higher than present report. In the present study reason was knowledge gap because of the belief of enough milk. This indicates the need to intensify the educational programmes of IYCF practices.

Early CF: $21.8 \%$ of mothers in the current study population initiated early feeds and is similar to the observation of Rishikesh study [13] where it was $25.2 \%$. The reason in our study was elder's advice who attributed excessive cry of the baby to insufficient milk production.

Quantity \& Frequency: In the current study $66.4 \%$ of mothers were giving ideal quantity. But only $25.5 \%$ of mothers were giving feeds at recommended frequency and it is much lower than Rishikesh study [13] who reported 65\% . And in Aggarwal's study [11] it was only $39.3 \%$. As the present study was done in rural based back ground the practice gap might be high.

Quality of CF: $77.7 \%$ of mothers in the present study were giving homemade feeds and is comparable to S.Rao's study [15] and commercial preparation users were only $18.6 \%$ in contrast to $55.6 \%$ of commercial users in Rishikesh study [13].

Others: Greens were used by $15.9 \%$ of mothers of children of 12-23 months of age and is much lower to Rishikesh study where it was $25.5 \%$. $12.7 \%$ of mothers were giving eggs and consumption of poultry was observed $0.9 \%$ in the present study. Snacks were 
received by $80.9 \%$ of subjects. This is the first study that included these details.

Present study observed impact of parent's education and socio-economic status on complementary feeding practices. Similar observation reported in Aggarwal et al and S. Rao et al. In the current study influence of father's education was also assessed and positive correlation was recorded. Father's participation was very encouraging. This is the first study that assessed role father's educational status from this area. However, very small proportion (14.5\%) of mothers received knowledge of complementary feeding practices from qualified people. Utilizing the opportunities of immunization, and active role of Asha workers in spreading the knowledge of IYCF practices will improve the present status.

\section{Conclusions}

$40.9 \%$ of mothers in the current study initiated feeds at recommended time. Ideal quantity was given by $66.4 \%$ of mothers but only $25.5 \%$ were giving at right frequency. Diversity of feeds was observed in $23 \%$ of children. All these practices lead to malnutrition at this tender age. As there is increasing evidence for the positive impact of feeding counseling on energy and nutrient intake and growth in children of less than two years, changes in individual's behavior, supplemental interventions will be needed. Effective nutrition actions do exist but should be implemented on a sufficiently large scale to reduce the burden of malnutrition.

Limitations: Present study was a hospital based. Community based studies are required to know the actual situation. The study data was collected on a recall basis hence recall bias exists.

Dr. K.Sailaja: Conception, Design, Interpretation of data, Critical revision of the manuscript for important intellectual content

Dr. Kiran Haridas: Acquisition of data, analysis, Drafting the manuscript.

Funding: Nill, Conflict of Interest: None

Permission of IRB: Yes

\section{References}

1. WHO. Complementary feeding: report of the global consultation [Internet]. Who.int. 2016 [cited 5 December 2015]. Available from: http://www.who.int/maternal_child_adolescent/docume nts/924154614X/en/

2. India. Ministry of Health and Family Welfare. Guidelines for Enhancing Optimal Infant and Young Child Feeding Practices. New Delhi: Ministry of Health and Family Welfare; 2013. P.5,41

3, .Complementary feeding [Internet]. World Health Organization. 2016 [cited 10 December 2015]. Available from: http://www.who.int/nutrition/topics/complementary_fee ding/en/

4. Global Nutrition Report 2015. Actions and Accountability to Advance Nutrition and Sustainable Development. Page-2. Available at http://ebrary.ifpri.org/utils/getfile/collection/p15738coll 2/id/129443/filename/129654.pdf

5. Elizabeth K E. Nutrition and Child Development. 5th ed. Paras Medical Publishers; 2015.

6. The Healthy Growth Project [Internet]. World Health Organization. 2016 [cited 9 January 2016]. Available from:

http://www.who.int/nutrition/healthygrowthproj/en/inde $\mathrm{x} 2 . \mathrm{html}$

7. Kumar N, Kishore J, Gupta N. Kuppuswamy's socioeconomic scale: Updating income ranges for the year 2012. Indian Journal of Public Health. 2012;56(1):103.

8. WHO. Complementary Feeding Counseling Training Course. 2002.

9. WHO. Infant \& Young Child Feeding- Student's Handbook. 2012-13

10. National Family Health Survey-4, 2015-16 State Fact Sheet [Internet].2016[cited 16 January 2016]. Available from: http://rchiips.org/nfhs/pdf/NFHS4/TG_FactSheet.pdf

11. Aggarwal A, Verma S, Faridi M; Dayachand. ateness in timing, quantity and consistency. Indian J Pediatr .2008 Jan;75(1):49-53.

12. Sethi V, Kashyap S, Seth V. Effect of nutrition education of mothers on infant feeding practices. Indian J Pediatr. 2003;70(6):463-466. 
13.Vartika S, Kumar P. Complementary Feeding Practices in Rural Communiy: A Study from block Doiwala district Dehradun .Indian J Basic and Applied Medical research: 2014;3(2):358-363.

14.Roy S, Dasgupta A, Pal B. Feeding Practices of Children in an Urban Slum of Kolkota. Indian J Community Medicine: 2009:34(4)362-363.
15. Rao S, Swathi PM, Unnikrishnan B, Hegde A. Study of Complementary Feeding Practices among Mothers of Children aged six months to two years - A study from Coastal South India. Australian Medical Journal: 2011:4(5):252-257.

DOI

\section{How to cite this article?}

K Sailaja, Kiran H, Complementary feeding practices in rural areas of Telangana: A hospital based, cross-sectional, descriptive study : Int J Pediatr Res 2016;3(3):156-161. doi:10.17511/ijpr.2016.i03.04. 